\title{
CORRIGENDUM
}

\section{The targeted delivery of multicomponent cargos to cancer cells by nanoporous particle-supported lipid bilayers}

Carlee E. Ashley, Eric C. Carnes, Genevieve K. Phillips, David Padilla, Paul N. Durfee, Page A. Brown, Tracey N. Hanna, Juewen Liu, Brandy Phillips, Mark B. Carter, Nick J. Carroll, Xingmao Jiang, Darren R. Dunphy, Cheryl L. Willman, Dimiter N. Petsev, Deborah G. Evans, Atul N. Parikh, Bryce Chackerian, Walker Wharton, David S. Peabody

and C. Jeffrey Brinker

Nature Materials 10, 389-397 (2011); published online 17 April 2011; corrected online 10 May 2011.

In the version of this Letter originally published, in Fig. 1 a double bond in the maleimide cycle of the crosslinker molecular structure was missing; the definition of the SP94 peptide in the text should have read H2N-SFSIIHTPILPLGGC-COOH; and in Fig. 6a the lowest value of the right-hand $y$ axis should have read $10^{6}$. These errors have now been corrected in the HTML and PDF versions. 